doi:10.1016/j.puhe.2006.06.005

Copyright (c) 2006 The Royal Institute of Public Health Published by Elsevier Ltd.

\title{
Using registries in general practice to estimate countrywide morbidity in The Netherlands
}

\author{
Ronald Gijsen ${ }^{a} *$ and Marinus J.J.C. Poos ${ }^{a}$ \\ ${ }^{a}$ National Institute for Public Health and the Environment, Bilthoven, The \\ Netherlands \\ ${ }^{*}$ Corresponding author. Tel.: +313027439 50; fax: +3130274 4450.
}

\section{Summary}

\section{Objective}

Examining the possibility of using data from registries in general practice in order to present morbidity figures concerning a broad range of major diseases for the Dutch population.

\section{Study design}

Qualitative and quantitative analysis of registered diagnoses.

\section{Methods}

Quantitative data from six registries were obtained. In addition, information about the registration process was obtained and discussed with representatives of the registries. Subjects for discussion were the general characteristics of the registries and disease-specific rules.

\section{Results}

Some important differences exist in the characteristics of the registries and the disease-specific coding rules for computing incidence and prevalence. However, for most diseases the rules of two or more registries corresponded with each other, so that a selection of registries that measured the occurrence of a particular disease in a similar way could be made. Nevertheless, for some age categories rather large differences between registries were observed. The best estimates for the whole country were calculated as the average incidence and prevalence of the selected registries.

\section{Conclusions}

Data that were originally obtained during patient care can be made usable for public health policy purposes. To further improve the quality of data and to increase the usefulness of these data for public health policy purposes, more efforts are required. 
Public Health Volume 120, Issue 10 , October 2006, Pages 923-936

\section{Introduction}

Governments need objective information about the health status of their people. This information can be used to prioritize goals and evaluate public health policy. Nowadays almost every European country has its own system to describe the national public health situation. ${ }^{1}$ In the Netherlands, we have the Dutch Public Health Status and Forecasts Report and accompanying websites for background information. ${ }^{2,3}$ and 4 Core indicators for describing public health are selected, for example life expectancy, healthy life expectancy, incidence and prevalence, and mortality for a selection of diseases. For the purpose of the Dutch report 53 diseases that contribute to a large extent to the total burden of disease were selected. ${ }^{5}$

Ideally, every country has data on a large number of health indicators that are continuously measured and representative of the whole population as well as for subgroups within the population. Unfortunately such a data system does not exist in any country. Consequently, to describe the health of a nation, researchers have to deal with a diversity of data sources: mortality statistics, healthcare registries, health examination surveys, and health interview surveys. In most countries data concerning the occurrence of diseases come from health interview surveys measuring self-reported diseases. Although surveys give a certain picture of the total burden of disease in a population, the observed morbidity is not reviewed by medical experts. Often very mild morbidity is included, which is less relevant with regard to the serious disabling burden of disease and healthcare utilization. Therefore, it might be advantageous also to use data from registries in general practice that only count cases that seek medical care and are diagnosed or reviewed by a physician. ${ }^{6}$

The opportunity to derive information from general practice registries for public health purposes is greater in countries where people are listed by name in a general practice, so that the underlying practice population by age and sex is known and the denominator of the epidemiological fraction can be determined. Another favourable aspect is a situation in which direct access to a medical specialist and other forms of care is only possible after a referral from the general practitioner (GP). In countries like the Netherlands, the UK, Denmark, Norway, Slovenia, Croatia, Italy, and Portugal these conditions are fulfilled to a large extent. $^{7,} 8$ and 9

Accordingly, in this study we examined how data from registries in general practice can be used to estimate the incidence and prevalence of diseases in the Dutch population. First, we describe the Dutch primary care system, because this contributes to the interpretation of the data. We show the opportunities of this approach for other countries that may be considering the use of these kinds of data for describing the health status of their populations, but also display the shortcomings. Finally, we give some suggestions for improvements in the use of these data.

\section{Dutch context}

In the Netherlands nearly all people are registered by name in a general practice over a long period of time. The few exceptions are the homeless, illegal and uninsured people, people who have forgotten to register because they have recently moved, and people staying in nursing homes. Altogether the group of people not registered in a general practice make at most a few percent of the Dutch population. In general, the GP operates as a 'gatekeeper'. ${ }^{10}$ With the 
exception of emergency cases and part of the care for sexually transmitted diseases (STDs), health problems will first be presented to the GP. If necessary, the GP refers to another primary healthcare worker or to a medical specialist. After a referral, a visit to an Accident and Emergency (A\&E) department, or after hospital admission, the GP is informed about the medical findings (e.g. diagnosis and laboratory results) and interventions. During out-of-hours, GPs work in largescale GP cooperatives, analogous to the UK and Denmark. Following a visit to the GP cooperatives, information is passed on to the patients' own GP.

Until 2005, access to general practice for socially insured people was free. Privately insured people could choose for an own risk and if they did, consultations were charged. Since 2006 the distinction between social and private insurance has been abolished, and all people can choose for a personal excess (in order to reduce the monthly costs of their health insurance package).

The majority of the general practices in the Netherlands have computerized patient registration (electronic patient records). However, electronic registries of individual GPs, GP cooperatives, A\&E departments, and medical specialists are seldom interchangeable. Also, A\&E departments and medical specialists often use only a paper archive.

\section{Methods}

Since the 1970s several registries in general practice have been started in the Netherlands. Some of them still exist; others have been stopped or have been incorporated into other registries. These registries combine the information from separate general practices into a broader framework. In 1995, the start of the current project, we selected five registries for describing morbidity in the Netherlands (see Table 1). The criteria for selection were: registration of the epidemiology of diseases (in contrast to the number of contacts with a GP), registration of a broad range of diseases, a long history of registration, availability of background information (books, reports, articles) and a considerable size of the total practice population. It was not possible to declare one registry as the most valid one.

In 1995 representatives of the registries were visited to judge the information in each of the registries. Not only were the general registration procedures discussed, but also the disease-specific registration rules, as these procedures and rules determine which cases are registered in the end. This information is important for interpreting differences in incidence and prevalence between registries. In 2000, the information was updated and again presented to and discussed with the representatives of the registries. Also, information from a sixth registry was added, because by this time this registry also had a reasonable population size and registered the incidence and prevalence of all diseases.

Of the 53 diseases selected for the Dutch Public Health Report, we considered for which diseases we could use registries in general practice. For some diseases other reliable data sources exist, for example the national cancer registry. For some rare diseases, like the sepsis syndrome, registries in general practice are not useful because the frequency in general practice is too low. Finally, for 25 diseases the data from registries in general practice were relevant. The general practice registries provided us with prevalence and incidence figures for men and women in each 5-year age group. One-year incidence and 1-year prevalence 
figures were calculated. To minimize the effect of random fluctuation, several years were averaged for most registries.

In this article we present two examples, the incidence of acute myocardial infarction and the prevalence of rheumatoid arthritis. For acute myocardial infarction we were able to validate the incidence figures as incidence figures have recently been published that were computed from record linkage of the National Medical Register of hospital admissions and the national statistics on the causes of mortality. ${ }^{18}$

\section{Results}

\section{Characteristics of the registries}

In Table 1 some of the characteristics of the six selected Dutch registries in general practice are presented. The characteristics of each registry are to a certain extent a consequence of its goal. Measuring morbidity is but a secondary goal for some of the registries. Other goals are serving as an index population for more in-depth research, measuring quality and utilization of care, and the teaching of medical students. In all registries diagnoses were based on the diagnostic criteria in the Dutch medical standards (published in the scientific journal Huisarts en Wetenschap ('General Practitioner and Science') and on the website http://nhg.artsennet.nl/). These standards exist for a large proportion of the diseases that are presented to general practice. For the few diseases without a medical standard, the ICPC- 2 criteria $^{19}$ or ICHPPC-2-defined criteria ${ }^{20}$ were used. The Sentinel Practice Network, however, used ad-hoc definitions (often derived from the medical standards). In five of the six registries, GPs register diagnoses using an electronic information system, mostly during patient contact. These information systems are also used for daily patient care. Periodically each registry extracts the epidemiological information from the electronic information system. Only in the Dutch Sentinel Practice Network are the GP's diagnoses coded in a paper form designed specially for epidemiologic registration.

\section{Disease-specific rules}

Which implicit or explicit rules are used in the six registries in defining episodes of disease or episodes of care? How are incidence and prevalence figures computed for each of the 25 diseases? In Table 2 we present this information with regard to the incidence of acute myocardial infarction and the prevalence of rheumatoid arthritis. For both diseases the Dutch Sentinel Practice Network had no recent data.

\section{Selection of registries}

After describing the disease-specific rules, disease-specific selections of registries were made. For each disease, separate for incidence and prevalence, we selected those registries that measured the occurrence of the disease in a valid way and if more than one registry was used the meaning of the figures from these registries had to be comparable. Examples of factors that played a role in the decision: the figures from the registries are unambiguous; the diagnosis is made by the GP or the diagnosis is submitted by the medical specialist; for 'common diseases' the information gathered by the assistant is added to the registry; for chronic diseases patients who are treated by a medical specialist are also registered; for less common diseases (e.g. STDs), only registries that are large and representative of the whole country are selected. 
In the example of the incidence of acute myocardial infarction we selected five registries (Fig. 1) and in the example of the prevalence of rheumatoid arthritis we selected three registries (Fig. 2). The reasons for not selecting two registries for rheumatoid arthritis were the possible omission of prevalent patients treated by a medical specialist. The estimates for the whole country were calculated as the average incidence and average prevalence from the selected registries, separate for each 5-year age group and sex (the 'Dutch estimate'). Although the variation of the incidence of acute myocardial infarction among women older than 60 years for some age categories is rather large, the age pattern is similar in all registries (see Fig. 1). In addition to the examples of acute myocardial infarction and rheumatoid arthritis, this method was also used for the other selected diseases. This resulted in morbidity figures for 25 diseases.
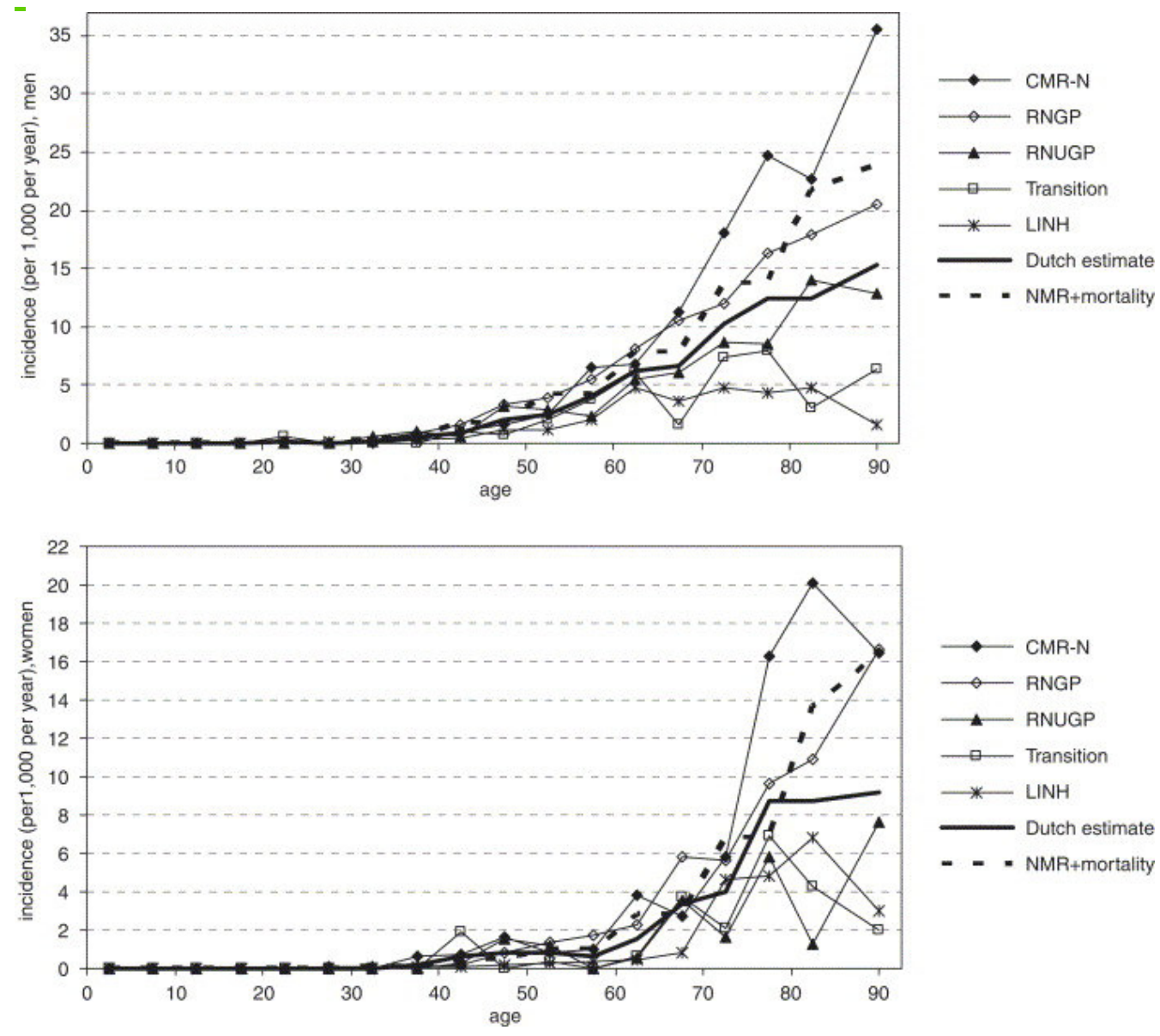

Figure 1. Incidence of acute myocardial infarction (men and women) according to five registries in general practice, a record linkage project of the National Medical Registration (NMR) and the National Mortality Statistics, ${ }^{17}$ and a Dutch estimate. For abbreviations see Table 1. 

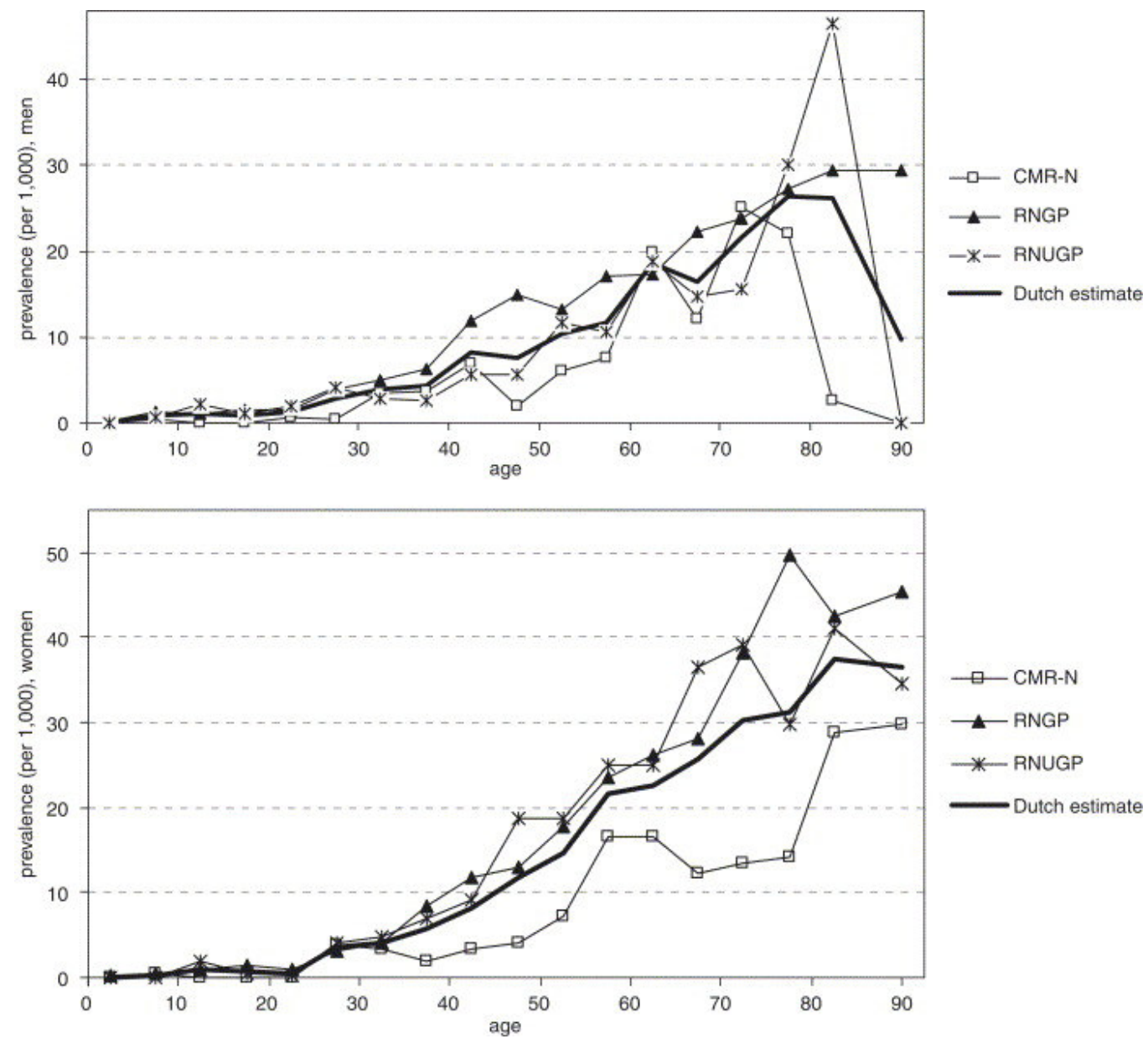

Figure 2. Prevalence of rheumatoid arthritis (men and women) according to three registries in general practice and a Dutch estimate. For abbreviations see Table 1.

\section{Validation}

In the case of acute myocardial infarction our estimate could be validated to an external data source, the record linkage of the National Medical Register of hospital admissions and the national statistics on the causes of mortality. ${ }^{18}$ For middle-aged and old men and women, our estimate corresponded quite well with the incidence from this different source (Fig. 1). For the oldest, the incidence of the record linkage project is clearly higher than the average incidence of all registries in general practice (for people younger than 70 the estimate from the record linkage project is $9 \%$ larger, and for people of 70 years and older $60 \%$ ).

\section{Discussion}

\section{Usefulness of registries in general practice for describing public health status}

In this study, we demonstrated that registries in general practice could be a source for estimates of incidence and prevalence figures of important diseases. By discussing the disease-specific rules used in the registries, a better understanding of the epidemiological figures could be gained. After selecting 
those registries that measure the occurrence of a particular disease in a welldefined and equivalent way, averages of incidences and prevalences could be computed. These were used to describe the health status of the Dutch population ${ }^{2}$ and 3 and formed the quantitative basis for the government policy document on prevention. ${ }^{21}$ and 22

In other countries, registries in general practice also exist. In countries where the

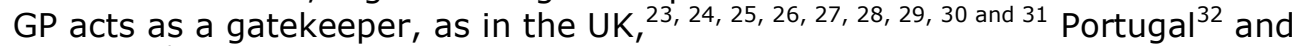
Italy, ${ }^{33}$ and 34 the conditions for their use are favourable. In many other countries, circumstances are less advantageous, because people have free access to secondary care and/or people are not listed by name in a general practice, which complicates the computation of a denominator. Nevertheless, in Belgium, ${ }^{35}$ and 36 Nordic countries, ${ }^{37}$ Sweden, ${ }^{38}$ and 39 France $^{40}$ and 41 and Ireland ${ }^{42}$ serious attempts have been made to generate epidemiological figures from these registries. A recent international comparison of the prevalence of diabetes mellitus in sentinel practice networks in Belgium, England, Croatia, France, the Netherlands, Portugal, Spain and Slovenia, concluded that the registries in these eight countries yield reasonable data. ${ }^{43} \mathrm{~A}$ challenge will be for European countries to generate valid epidemiological figures of various health problems on the basis of registries in general practice. However, great efforts are required to realize comparability of these figures. Estimates are not only dependent on the quality of the registries, but also on the healthcare organization in the country, reflected in the access to secondary care, the extent and type of care delivered by GPs, financial issues, and the need for a medical sick-leave certificate in the case of absence from work. ${ }^{37}$ These aspects all affect consulting rates and incidence and prevalence rates.

\section{Validity of combining figures to an average}

For the purposes of public health reporting, it is important to assess to what extent figures from general practices represent the real occurrence of diseases in the population. It is essential to realize that the morbidity based on registries in general practice reflects only health problems that are seen, recognized, and documented by medical professionals. Another question is how practices that participate in a registration project differ from those that do not. Research from England $^{44}$ and the Netherlands ${ }^{45}$ indicate only small differences. Certainly, data extracted from registries that are used in normal day-to-day patient care, are more complete than registries that collect data for special reasons. In the last mentioned type of registries, GPs will probably forget to register some of the findings. In the first mentioned type of registries, patient information can easily be supplemented with data from follow-up consultations, laboratory results or letters from medical specialists. Of the six Dutch systems, only one (the Dutch Sentinel Practice Network) collects data about specific diseases. This network was hardly used in the construction of epidemiological figures for the 25 diseases.

After the selection process, we calculated the best estimate for the country. We decided not to weigh the data to the size of the registries, because the size of the registry is but one of their important characteristics. The use of intensive quality systems and the experience of the GPs in registering morbidity are others. Weighting would result in decreasing the value of smaller registries without paying attention to these characteristics.

Nevertheless, it remains a point of concern whether the estimation is representative of the whole country with respect to geography as well as to population subgroups. The registries contain populations in urban, suburban, semi-rural and rural areas. Morbidity among the oldest is underestimated because 
nursing homes are not included in registries in general practice. However, for most diseases this effect is small, because less than $0.2 \%$ of the total Dutch population lives in a nursing home. For diseases like dementia and stroke, for which the underestimation might be substantial, epidemiological figures from GP registrations are supplemented with data from registrations in nursing homes. The computed figures might also underestimate the morbidity among other small high-risk groups, like homeless and illegal people.

The estimated incidence of acute myocardial infarction was validated by comparing it to another source (record linkage of the registrations of hospital admissions and mortality). For older people the GP-estimate was smaller than the estimate from the record linkage project. This difference can partly be explained by the incomplete view on the morbidity of the elderly by GPs (as described above). Another possibility is that deceased persons or persons who went into a nursing home remained on the practice list of the GPs for too long, so they contributed to the denominator, but not to the numerator of the epidemiological fraction. Finally, the record linkage project is not a gold standard; also mortality from uncertain causes like sudden death was included, which could have resulted in an overestimation of incidence rates.

\section{Variation between registries}

In spite of our selection process, the variation of the incidence and prevalence figures between the registries is considerable. Some causes of systematic differences between registries can be supposed. Firstly, differences in diseasespecific registration rules that were not clarified in our strategy, can explain part of the difference. This seems plausible since some registries do have systematically higher or lower figures. Secondly, at older ages, a greater part of the population lives in homes for the elderly. By chance it is possible that GPs in one registry serve more people in homes for the elderly than GPs in another one. Besides, in some of these institutions care is also delivered by medical specialists in nursing homes, so perhaps some GPs are not aware of all morbidity of these patients. Thirdly, differences between GPs in the alertness for comorbidity could have caused some of the differences in epidemiological rates. Finally, there are differences in practice populations with regard to socio-economic factors, ethnicity, and the social and physical environment. Registries are located in different regions of the country and the occurrence of risk factors, self-rated health, and healthcare utilization differs between regions. ${ }^{4}$

Variations in epidemiological data between registries in general practice do not only exist in the Netherlands, but were also observed in the UK ${ }^{43}, 44,45,46,47,48$ and 49 and the Nordic countries. ${ }^{37}$ Suggested causes of variation, above those mentioned, were the differences in classification or coding system, practice software, data quality control, definitions made for including or excluding patients, and completeness of information. This last item relates to the fact of whether or not information has been used from referrals, letters from other healthcare workers, hospitalizations, laboratory files, contacts with services of out-of-hours care, contacts by telephone and contacts with practice nurses or administrative staff.

\section{Suggestions for improvements}

Although we collected useful data from registries in general practice in the Dutch situation, some imperfections came to light. We think these do not only exist in the Netherlands, but also in other countries. Future activities in the Netherlands as well as in other countries can further improve the quality of data from 
registries and can increase the usefulness of these data for public health objectives.

1. Publishing the incidence and prevalence figures from the various registries, along with detailed descriptions of the characteristics and rules of the registries in one (Internet) system. Special attention should be given to the registration of morbidity of the elderly.

2. Publishing quality procedures of registries: how do registries look after the quality of the registration process and how do they tackle problems?

3. Improving the accessibility of the electronic information system for making selections of patients. For example, by extracting patients with diabetes from the system, it would be of surplus value when every registry can make a selection of those patients who satisfy the same criteria, such as patients with a recorded high blood glucose concentration. ${ }^{50}$ Second best is to check the data: how many of the selected diabetes patients do not have an indication of an elevated glucose concentration according to the electronic information system?

4. Correcting for socio-economic and geographic factors, for example by using the postcode, which gives information about the socio-economic status in a district.

5. Studying the quality of the data, and adjusting (if necessary) the definitions and rules. The quality of the data refers to reliability, internal validity (often defined as the completeness and correctness of the data) and external validity (sensitivity and positive predictive value). ${ }^{51}$ and 52 For example, inter-practice variation can be computed, ${ }^{53}$ registered data can be compared to the medical files maintained by the GP, ${ }^{11,14,54}$ and 55 or to external sources, such as patient questionnaires, ${ }^{11}$ and 56 cancer registry, ${ }^{57}$ and 58 registry of hospital admissions, ${ }^{59}$ and epidemiological population studies. ${ }^{12}$ and 59

6. Reviewing by representatives of the registration projects and users of the data. Such a group of experts can review the procedures, quality aspects, and outcomes of the registration projects. ${ }^{60}$ and 61 This review can be a meeting, an exchange of written questions and answers, or a visit by experts to a registry (audit).

A more extensive operation is to stimulate more GPs, or maybe all GPs, to register and contribute to a countrywide database. Extended collection, use and periodical extraction of data will offer an enormous opportunity for planning and monitoring the health service, measuring the quality of care and population-based research. ${ }^{62}$ and 63 This development is in accordance with pressure from society, the inspectorate, as well as professionals themselves on transparency (e.g. by developing and using performance indicators). Participation can be stimulated by accreditation, financial rewarding, and making available attractive software that is useful in daily practice and gives feedback to GPs. Financial punishment for not participating is another, less attractive, possibility. In this scenario of extended collection and use of data, caution must be paid to the quality of registration. In all probability, a countrywide registry without extensive agreement on definitions and rules, is outweighed by small, meticulous registries.

\section{Conclusion}

In this paper, we demonstrated that data originally intended for individual patient care in general practice, can be made usable for public health policy purposes. We have shown how we managed some difficulties in using these data to obtain 
estimates of the epidemiology of diseases. Bearing in mind the considerable variation between the registries, we appeal for further effort into the improvement of the quality of data. We hope that our experience can be helpful for public health researchers from other countries who are considering the use of data from registries in general practice.

\section{Acknowledgements}

The Dutch Ministry of Health, Welfare and Sport supported this research, within the framework of the Public Health Status and Forecasts. No other funds were used.

The authors thank the following persons:

- Representatives of the registries: Eloy $\mathrm{H}$. van de Lisdonk, PhD; Henk J. van den Hoogen, PhD; Henk Lamberts, Prof PhD; Inge M. Okkes, PhD; Cees van Boven, PhD; Marjan van den Akker, PhD; Job F. Metsemakers, PhD; François C.

Schellevis, Prof PhD; Michiel W. van der Linden, PhD; Margot W.M. de Waal, MSc; Aad I. Bartelds, PhD; Robert A. Verheij, PhD.

- Data-managers of the registries and the National Institute for Public Health and the Environment, a.o.: Sibo K. Oskam, MD; Johannes H.J. Bor, MD; Dirk-Jan Griffioen.

- Colleagues from the National Institute for Public Health and the Environment for their comments on former versions of this paper: Nancy Hoeymans PhD; Johannes A.M. van Oers, Prof PhD; Casper Schoemaker, PhD; Henriëtte F. Treurniet, PhD; Gert P. Westert, Prof PhD; Eveline A. van der Wilk, MSc, MPH.

\section{References}

1 Ward G, Cornelius-Taylor B, Brand H, Eisenhardt OH. Eva PHR Evaluation of National and Regional Public Health Reports. Bielefeld: 2003/02/05. Available at: http://www.eva-phr.nrw.de). Continued as PIA PHR.

2 van Oers JAM. Health on course? The 2002 Dutch public health status and forecasts report. RIVM Report No. 270551002. Houten: Bohn Stafleu Van Loghum; 2003.

3 National Public Health Compass (Nationaal Kompas Volksgezondheid), part of the Dutch Public Health Status and Forecasts, version 3.6, June 28, 2006. Available at:

http://www.nationaalkompas.nl/.

4 Dutch Atlas of Public Health (Nationale Atlas Volksgezondheid), part of the Dutch Public Health Status and Forecasts, version 3.6, June 28, 2006. Available at: http://www.zorgatlas.nl).

5 J.M. Melse, M.L. Essink-Bot, P.G. Kramers and N. Hoeymans, A national burden of disease calculation: Dutch disability-adjusted life-years. Dutch Burden of Disease Group, Am J Public Health 90 (2000), pp. 1241-1247.

6 D.M. Fleming, The measurement of morbidity in general practice, J Epidemiol Community Health 45 (1991), pp. 180-183. 
7 D.M. Fleming, F.G. Schellevis and W.J. Paget, Health monitoring in sentinel practice networks. The contribution of primary care, Eur J Public Health 13 (2003) (Suppl 3), pp. 80-84.

8 M. Schlaud, M.H. Brenner, M. Hoopmann and F.W. Schwartz, Approaches to the denominator in practice-based epidemiology: a critical overview, J Epidemiol Community Health 52 (1998) (Suppl 1), pp. S13-S19.

9 W.G.W. Boerma, Profiles of general practice in Europe: an international study of variation in the tasks of general practitioners, Nivel, Utrecht (2003).

10 G.P. Westert, L. Jabaaij and F.G. Schellevis, Morbidity, performance and quality in primary care. Dutch general practice on stage, Radcliffe Publishing, Abingdon (2006).

11 C. van Weel, Validating long term morbidity recordings, J Epidemiol Community Health 49 (1995) (Suppl 1), pp. 29-32.

12 LINH: National information network of GPs. Available at: (http://www.linh.nl/ $)$.

13 M. van den Akker, J.F.M. Metsemakers, C.B.G. Limonard and J.A. Knottnerus, General Practice. A goldmine for research. Data and scientific use of the Registration Network Family Practices, Department of General Practice, Maastricht University, Maastricht (2004).

14 V. van der Meer, M.W.M. de Waal, A.P. Timmers, G.H. de Bock and M.P. Springer, [How up-to-date are the medical records? Research on five locations.] Hoe up-to-date is het medisch dossier? Een onderzoek op vijf lokaties, Huisarts Wet 44 (2001), pp. 194-197.

15 I.M. Okkes, S.K. Oskam and H. Lamberts, The probability of specific diagnoses for patients presenting with common symptoms to Dutch family physicians, J Fam Pract 51 (2002), pp. 31-36.

16 A.I.M. Bartelds, Validation of Sentinel data, Gesundheitswesen 55 (1993) (Suppl 1), pp. 3-7.

17 G.P. Westert, F.G. Schellevis, D.H. de Bakker, P.P. Groenewegen, J.M. Bensing and J. van der Zee, Monitoring health inequalities through general practice: the Second Dutch National Survey of General Practice, Eur J Public Health 15 (2005), pp. 59-65.

18 H.L. Koek, L.A.T.M. van Leest, W.M.M. Verschuren and M.L. Bots, [Diseases of the circulatory system in the Netherlands 2004. Figures about lifestyle, risk factors, disease and mortality.] Hart- en vaatziekten in Nederland 2004. Cijfers over leefstijl- en risicofactoren, ziekte en sterfte, Nederlandse Hartstichting, Den Haag (2004).

19 I.M. Okkes, M. Jamoulle, H. Lamberts and N. Bentzen, ICPC-2-E: the electronic version of ICPC-2. Differences from the printed version and the consequences, Fam Pract 17 (2000), pp. 101-107.

20 Classification Committee of WONCA (World Organization of National Colleges, Academies, and Academic Associations of General Practitioners/Family Physicians), ICHPPC-2-defined, International Classification of Health Problems in Primary Care (3rd ed), Oxford University Press, Oxford/New York/Toronto (1986).

21 Ministry of Health, Welfare and Sport. Living longer in good health. Also a question of a healthy lifestyle. Netherlands Health-Care Prevention Policy. International Publication Series: Health, Welfare and Sport No. 19. The Hague, June 2003. Available at:

http://www.minvws.nl/en/themes/prevention//.

22 H.F. Treurniet, N. Hoeymans, R. Gijsen, M.J.J.C. Poos, J. A.M. van Oers and M.A.H. Thien, Health status and the challenges for prevention in The Netherlands, Public Health 119 (2005), pp. 159-166.

23 D.M. Fleming, Weekly Returns Service of the Royal College of General Practitioners, Commun Dis Public Health 2 (1999), pp. 96-100.

24 D.M. Fleming, K.W. Cross and M.A. Barley, Recent changes in the prevalence of diseases presenting for health care, Br J Gen Pract 55 (2005), pp. 589-595. 
25 T. Walley and A. Mantgani, The UK General Practice Research Database, Lancet 350 (1997), pp. 1097-1099.

26 I.M. Carey, D.G. Cook, S. De Wilde, S.A. Bremner, N. Richards and S. Caine et al., Developing a large electronic primary care database (Doctors' Independent Network) for research, Int J Med Inform 73 (2004), pp. 443-453.

27 J. Hippisley-Cox, D. Stables and M. Pringle, QRESEARCH: a new general practice database for research, Inform Primary Care 12 (2004), pp. 49-50.

28 McCormick, Fleming D, Charlton J. Morbidity statistics from general practice. Fourth national study 1991-1992. Series MB5 No. 3. London: HMSO; 1995.

29 P. Horsfield and S. Teasdale, Generating information from electronic patient records in general practice: a description of clinical care and gender inequalities in coronary heart disease using data from over two million patient records, Inform Primary Care 11 (2003), pp. 137-144.

30 S. De Lusignan, P.N. Stephens, N. Adal and A. Majeed, Does feedback improve the quality of computerized medical records in primary care?, J Am Med Inform Assoc 9 (2002), pp. 395-401.

31 F.G. Whitelaw, S.L. Nevin, R.M. Milne, R.J. Taylor, M.W. Taylor and A.H. Watt, Completeness and accuracy of morbidity and repeat prescribing records held on general practice computers in Scotland, Br J Gen Pract 46 (1996), pp. 181-186.

32 J.A. Dias, M.M. Felgueiras, J.P. Sanchez, J.M. Goncalves, J.M. Falcao and Z.P. Pimenta, The prevalence of Parkinson's disease in Portugal. A population approach, Eur J Epidemiol 10 (1994), pp. 763-767.

33 A. Filippi, D. Vanuzzo, A.A. Bignamini, G. Mazzaglia, C. Cricelli and A.L. Catapano, The database of Italian general practitioners allows a reliable determination of the prevalence of myocardial infarction, Ital Heart J 6 (2005), pp. 311-314.

34 C. Cricelli, G. Mazzaglia, F. Samani, M. Marchi, A. Sabatini and R. Nardi et al., Prevalence estimates for chronic diseases in Italy: exploring the differences between self-report and primary care databases, J Public Health Med 25 (2003), pp. 254-257.

35 D. Devroey, V. Van Casteren and F. Buntinx, Registration of stroke through the Belgian Sentinel Network and factors influencing stroke mortality, Cerebrovasc Dis 16 (2003), pp. 276-279.

36 A. Van den Bruel, S. Bartholomeeusen, B. Aertgeerts, C. Truyers and F. Buntinx, Serious infections in children: an incidence study in family practice, BMC Fam Pract 7 (2006), p. 23.

37 A. Grimsmo, E. Hagman, E. Faiko, L. Matthiessen and T. Njalsson, Patients, diagnoses and processes in general practice in the Nordic countries. An attempt to make data from computerised medical records available for comparable statistics, Scand J Primary Health Care 19 (2001), pp. 7682.

38 S. Engström, S. Mölstad, G. Nilsson, K. Lindström and L. Borgquist, Data from electronic patient records are suitable for surveillance of antibiotic prescriptions for respiratory tract infections in primary health care, Scand J Infect Dis 36 (2004), pp. 139-143.

39 J. Månsson, G. Nilsson, C. Björkelund and L. Stender, Collection and retrieval of structured clinical data from electronic patient records in general practice. A first-phase study to create a health database for research and quality assessment, Scand J Primary Health Care 22 (2004), pp. 6-10.

40 OMG, Observatoire de la Medecine Générale. Available at: http://omg.sfmg.org

41 F. le Pont, L. Letrilliart, V. Massari, Y. Dorleans, G. Thomas and A. Flahault, Suicide and attempted suicide in France: results of a general practice sentinel network, 1999-2001, Br J Gen Pract 54 (2004), pp. 282-284. 
42 B. O'Mahony, M. Fennessy, A.M. Lanigan, C. Lynch, O. O'Reilly and Y. O'Neill, Morbidity data collection in general practice: experience in the South Eastern Health Board 1998-1999, Ir Med J 94 (2001), pp. 299-300,302.

43 D.M. Fleming, F.G. Schellevis and V. van Casteren, The prevalence of known diabetes in eight European countries, Eur J Public Health 14 (2004), pp. 10-14.

44 V. Hammersley, J. Hippisley-Cox, A. Wilson and M. Pringle, A comparison of research general practices and their patients with other practices-a cross-sectional survey in Trent, $\mathrm{Br}$ J Gen Pract $\mathbf{5 2}$ (2002), pp. 463-468.

45 G.P. Westert, L.H.F. Hoonhout, D.H. de Bakker, H.J.M. van den Hoogen and F.G. Schellevis, [General practitioners with and without electronic computerized patient registration: little difference in medical acting] Huisartsen met en zonder elektronisch medisch dossier: weinig verschil in medisch handelen, Huisarts Wet 45 (2002), pp. 58-62.

46 D.M. Fleming, A.M. Ross, K.W. Cross, H. Kendall and A.J. Elliot, Concerning: 'Why has antibiotic prescribing for respiratory illness declined in primary care? A longitudinal study using the General Practice Research Database', J Public Health 27 (2005), pp. 228-229.

47 M. Ashworth, R. Latinovic, J. Charlton, K. Cox, G. Rowlands and M. Gulliford, Why has antibiotic prescribing for respiratory illness declined in primary care? A longitudinal study using the General Practice Research Database, J Public Health 26 (2004), pp. 268-274.

48 S. de Wilde, I.M. Carey, S.A. Bremner, N. Richards, S.R. Hilton and D.P. Strachan et al., A comparison of the recording of 30 common childhood conditions in the Doctor's Independent Network and General Practice Research Databases, Health Stat Q 22 (2004), pp. 21-31.

49 A. Newnham and R. Ryan, Prevalence of diagnosed diabetes mellitus in general practices in England and Wales, 1994 to 1998, Health Stat Q 14 (2002), pp. 5-13.

50 R. Lawrenson, T. Williams and R. Farmer, Clinical information for research; the use of general practice databases, J Public Health Med 21 (1999), pp. 299-304.

$51 \mathrm{~K}$. Thiru, A. Hassey and F. Sullivan, Systematic review of scope and quality of electronic patient record data in primary care, BMJ 326 (2003), pp. 1070-1072 [Extended text available on BM] website].

$52 \mathrm{~K}$. Jordan, M. Porcheret and P. Croft, Quality of morbidity coding in general practice computerized medical records: a systematic review, Fam Pract 21 (2004), pp. 396-412.

53 G.P. Westert, D.H. de Bakker and F.G. Schellevis, [Interdoctor and interpractice variation among and between registries in general practice. A secondary analysis.] Interdokter- en interpraktijkvariatie binnen en tussen huisartsregistraties. Een secundaire analyse, Huisarts Wet 42 (1999), pp. 18-2130.

54 J.F. Metsemakers, Unlocking the patients' records in general practice for research, medical education and quality assurance: the registration network family practices, Thesis Publishers, Amsterdam (1994).

55 F.G. Schellevis, E. van de Lisdonk, J. van der Velden, J.T. Eijk and C. van Weel, Validity of diagnoses of chronic diseases in general practice, J Clin Epidemiol 46 (1993), pp. 461-468.

56 A.D. Mohangoo, M.W. van der Linden, F.G. Schellevis and H. Raat, Prevalence estimates of asthma or COPD from a health interview survey and from general practitioner registration: what's the difference?, Eur J Public Health 16 (2006), pp. 101-105.

57 L.J. Schouten, P. Höppener, P.A. van den Brandt, J.A. Knottnerus and J.J. Jager, Completeness of cancer registration in Limburg, the Netherlands, Int J Epidemiol 22 (1993), pp. 369-376.

58 J.A. Kaye, L.E. Derby, M. del Mar Melero-Montes, M. Quinn and H. Jick, The incidence of breast cancer in the General Practice Research Database compared with national cancer registration data, $\mathrm{Br}$ J Cancer 83 (2000), pp. 1556-1558. 
Public Health Volume 120, Issue 10 , October 2006, Pages 923-936

59 J. Mant, R.J. McManus, R. Hare and P. Mayer, Identification of stroke in the community: a comparison of three methods, Br J Gen Pract 53 (2003), pp. 520-524.

60 J.A. Knottnerus, [Morbidity registration in general practice. About diversity of goals and requirements.] Registeren van morbiditeit in de huisartsgeneeskunde. Over diversiteit van doelstellingen en vereisten, Huisarts Wet 37 (1994), pp. 136-141.

61 J.G. Deckers, W.J. Paget, F.G. Schellevis and D.M. Fleming, European primary care surveillance networks: their structure and operation, Fam Pract 23 (2006), pp. 151-158.

62 A. Majeed, Sources, uses, strengths and limitations of data collected in primary care in England, Health Stat Q 21 (2004), pp. 5-14.

63 S. de Lusignan and C. van Weel, The use of routinely collected computer data for research in primary care: opportunities and challenges, Fam Pract 23 (2006), pp. 253-263. 